\title{
磷肥用量对甜玉米磷素吸收利用的影响
}

\author{
颜晓军 1,2 叶德练 2,3 苏达 2,3 李 芳 ${ }^{1,2}$ 郑朝元 ${ }^{1,2}$ 吴良泉 ${ }^{1,2, *}$ \\ ${ }^{1}$ 福建农林大学资源与环境学院, 福建福州 $350002 ;^{2}$ 福建农林大学国际镁营养研究所, 福建福州 $350002 ;{ }^{3}$ 福建农林大学农学院, \\ 福建福州 350002
}

摘 要: 明确磷素吸收利用特性, 是磷素高效利用及作物高产的基础。本研究通过 2 年田间磷肥梯度定位试验, 研究不 同磷肥供应 $\left(0 、 37.5 、 75 、 150\right.$ 和 $300 \mathrm{~kg} \mathrm{hm}^{-2}$, 分别用 P0、P1、P2、P3 和 P4 表示)对甜玉米产量、不同器官生物量和 磷素累积与分配、磷素转运特征和磷肥利用效率的影响。结果表明, 磷肥供应均显著提高 2018 年和 2019 年甜玉米的鲜 穗产量, 但不同磷肥供应处理 (P1 P4) 之间的产量差异不显著, 磷肥供应显著提高甜玉米拔节期、吐丝期和鲜食期植 株的生物量及磷素累积量, 其中籽粒磷素累积量约占植株磷素累积量的 $42 \%$ 。磷肥供应下花后磷同化对甜玉米穗部磷 素累积量的贡献率达到 $57.3 \%$ 93.0\%; 而 1 kg 磷素生产鲜穗量、磷素生理效率、农学效率、回收利用率和偏生产力均 随着磷肥供应量增加而明显下降。综合考虑产量与磷肥利用效率, 在本试验条件下, $37.5 \mathrm{~kg} \mathrm{hm}^{-2}$ 磷肥供应可满足甜玉米 高产和磷肥高效利用的需求。

关键词: 甜玉米; 磷肥水平; 产量; 磷素利用

\section{Effects of phosphorus application on phosphorus uptake and utilization of sweet corn}

\author{
YAN Xiao-Jun ${ }^{1,2}$, YE De-Lian ${ }^{2,3}$, SU Da ${ }^{2,3}$, LI Fang ${ }^{1,2}$, ZHENG Chao-Yuan ${ }^{1,2}$, and WU Liang-Quan ${ }^{1,2, *}$ \\ ${ }^{1}$ College of Resources and Environmental Sciences, Fujian Agriculture and Forestry University, Fuzhou 350002, Fujian, China; ${ }^{2}$ International Mag- \\ nesium Institute / Fujian Agriculture and Forestry University, Fuzhou 350002, Fujian, China; ${ }^{3}$ College of Agriculture, Fujian Agriculture and Forestry \\ University, Fuzhou 350002, Fujian, China
}

\begin{abstract}
Understanding the phosphorus (P) absorption mechanism is the premise for high P utilization and high crop yield. In this study, the effects of different $\mathrm{P}$ rates $\left(0,37.5,75,150\right.$, and $300 \mathrm{~kg} \mathrm{hm}^{-2}$, expressed as $\mathrm{P} 0, \mathrm{P} 1, \mathrm{P} 2, \mathrm{P} 3$, and $\mathrm{P} 4$, respectively) on sweet corn yield, biomass and $\mathrm{P}$ accumulation and tissue distribution, $\mathrm{P}$ transportation and $\mathrm{P}$ utilization were studied using a two-year P gradient positioning field experiment. Our results showed that $\mathrm{P}$ application significantly increased the fresh ear yield of sweet corn, but the yield difference among different P application rates (P1-P4) was not significant from 2018 to 2019 compared with P0 treatment. P application significantly increased the biomass and $\mathrm{P}$ accumulation of sweet corn plants at jointing, silking and fresh eating stages, respectively. In addition, $\mathrm{P}$ accumulation in grain was not significant different, which accounting for $42 \%$ of plant $\mathrm{P}$ accumulation. With $\mathrm{P}$ application, the contribution rate of $\mathrm{P}$ assimilation to the ear $\mathrm{P}$ accumulation was 57.3\%-93.0\% after anthesis, while the fresh ear yield per $\mathrm{P}$ accumulation, $\mathrm{P}$ physiological efficiency, agronomic efficiency, recovery efficiency and partial productivity decreased with $\mathrm{P}$ rates. Considering the yield and utilization efficiency of phosphate fertilizer, the supply of $37.5 \mathrm{~kg} \mathrm{hm}^{-2}$ of phosphate fertilizer can meet the needs of high yield and efficient utilization of phosphate fertilizer in sweet corn in this experiment.
\end{abstract}

Keywords: sweet corn; phosphorus application rate; yield; phosphorus utilization

\footnotetext{
本研究由国家重点研发计划项目(2017YFD0200200, 2017YFD0200207, 2016YFD0200400, 2016YFD0200401), 国家自然科学基金青年 项目 $(41601244,31701367,2019 J 01374)$ 和福建省教育厅中青年教师科研项目(JAT160174, JAT170157, JAT170156)资助。

This study was supported by the National Key Research and Development Program of China (2017YFD0200200, 2017YFD0200207, 2016YFD0200400, 2016YFD0200401), the Youth Program of National Natural Science Foundation of China (41601244, 31701367, 2019J01374), and the Scientific Research Project of Young and Middle-aged Teachers in Fujian Education Department (JAT160174, JAT170157, JAT170156). *通信作者(Corresponding author): 吴良泉, E-mail: liangquan01@163.com

第一作者联系方式: E-mail: 16565710@qq.com

Received (收稿日期): 2020-03-06; Accepted (接受日期): 2020-08-19; Published online (网络出版日期): 2020-09-11.

URL: https://kns.cnki.net/kcms/detail/11.1809.S.20200910.0921.002.html
} 
甜玉米是我国重要的特色经济作物, 又称为水果(蔬 菜)玉米 ${ }^{[1]}$ 。近年来, 由于市场需求大, 经济效益显著 ${ }^{[2-3]}$, 我国甜玉米种植面积逐年增加, 目前已超过 $4 \times 10^{5} \mathrm{hm}^{2[4]}$ 。 同时发展甜玉米产业也是响应国家调减普通玉米、适当扩 增鲜食玉米种植面积的号召, 对我国种植业供给侧改革 具有重要意义。

磷素是作物的必需营养元素, 参与植物生长和细胞 代谢 ${ }^{[5]}$ 、光合磷酸化、三羧酸循环等生理过程 ${ }^{[6]}$, 合理的 磷肥运筹对作物产量的提高至关重要 ${ }^{[7]}$ 。有研究认为磷肥 施入红壤中容易被固定、沉淀, 导致速效磷浓度较低, 生 产上往往施用大量的磷肥来保障作物高产 ${ }^{[8]}$ 。但是磷肥过 量施用不仅导致土壤磷素累积、磷肥当季利用率降低 ${ }^{[9]}$ 、 环境负荷加大等问题 ${ }^{[10]}$, 还无益于提高产量, 甚至导致 减产 ${ }^{[11-12]}$ 。明确磷素在作物体内的吸收转运规律是实现磷 肥合理施用的关键。前人研究表明普通玉米植株磷素累积 随着生育期推进而增加, 在鲜食期达到峰值后趋于平 缓 ${ }^{[13]}$ 。生殖发育阶段, $56.0 \%$ \% $5.8 \%$ 的磷素依赖于营养器 官的转运 ${ }^{[14]}$ 。而且磷素的吸收和转运对不同种植区域和 基因型等的响应存在差异 ${ }^{[15-18]}$ 。考虑到甜玉米和普通玉米

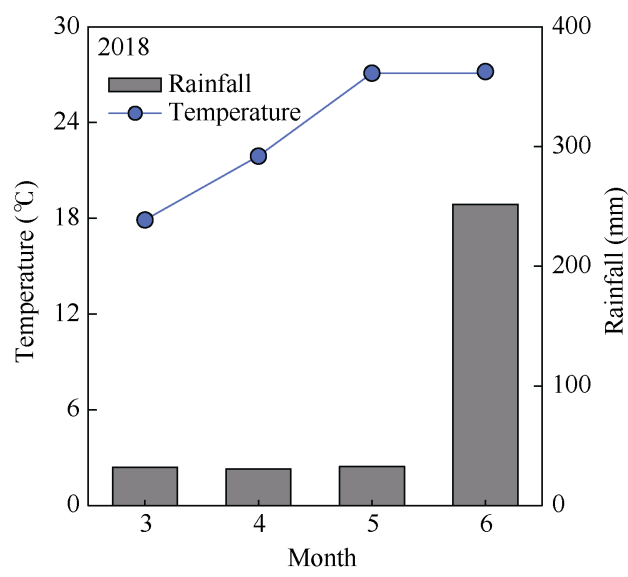

在生育期、品种特性和环境响应的敏感度等方面差异较大, 因此明确甜玉米磷素的吸收利用特性对优化甜玉米磷肥 管理显得尤为重要, 但是关于甜玉米磷素吸收利用特征 响应不同磷肥供应的研究尚少见报道。

本研究通过连续 2 年磷肥梯度定位试验, 比较不同磷 肥供应水平对甜玉米鲜穗产量、磷素累积与分配和磷肥利 用效率的影响, 明确甜玉米植株磷素累积动态及转运规 律, 以期为甜玉米磷肥合理施用及高产高效生产提供理 论依据。

\section{1 材料与方法}

\section{1 试验区基本概况}

试验于福建省漳州市诏安县桥东镇内凤村正禾农场 进行 $\left(117.22^{\circ} \mathrm{E}, 23.72^{\circ} \mathrm{N}\right)$ 。该种植区域属亚热带季风气候, 温暖多雨、光热充足, 季节间降雨量差异较大。甜玉米生 育期月均温及月降水量见图1。试验地土壤类型为赤沙土, 含有机质 $8.28 \mathrm{~g} \mathrm{~kg}^{-1}$ 、碱解氮 $12.67 \mathrm{mg} \mathrm{kg}^{-1}$ 、全氮 $0.60 \mathrm{~g}$ $\mathrm{kg}^{-1}$ 、速效磷7.10 mg kg $\mathrm{m}^{-1}$ 、全磷 $0.16 \mathrm{~g} \mathrm{~kg}^{-1}$ 、速效钾 40.17 $\mathrm{mg} \mathrm{kg}^{-1}, \mathrm{pH} 5.90$ 。

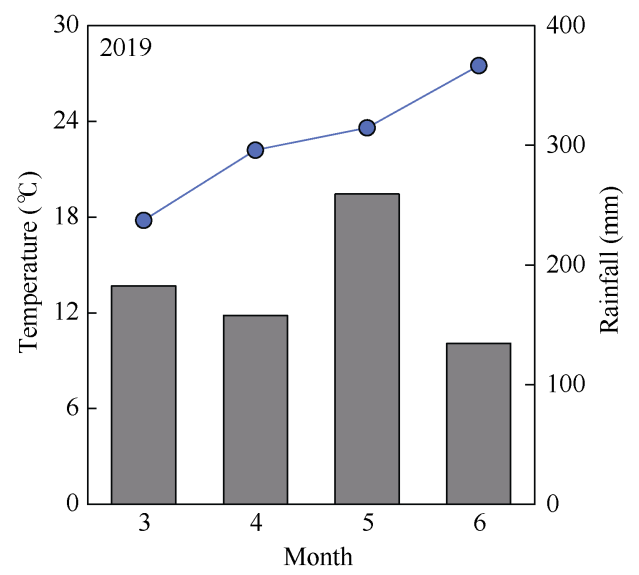

图 1 甜玉米生育期诏安月均平均气温与降雨量

Fig. 1 Temperature and rainfall amount during the sweet corn growth period in Zhaoan

\section{2 试验设计}

本试验采用完全随机区组设计, 设置 5 个磷肥 $\left(\mathrm{P}_{2} \mathrm{O}_{5}\right)$ 水平, 分别为 $P 0\left(0 \mathrm{~kg} \mathrm{hm}^{-2}\right) 、 P 1\left(37.5 \mathrm{~kg} \mathrm{hm}^{-2}\right) 、 P 2(75 \mathrm{~kg}$ $\left.\mathrm{hm}^{-2}\right) 、 \mathrm{P} 3\left(150 \mathrm{~kg} \mathrm{hm}^{-2}\right)$ 和 P4 $\left(300 \mathrm{~kg} \mathrm{hm}^{-2}\right)$, 每个处理 3 次重复, 小区面积为 $75 \mathrm{~m}^{2}$ 。磷肥于移栽前(移栽前 $1 \mathrm{~d}$ ) 一 次性穴施, 并与土壤混合搅拌均匀; 氮肥(N)用量为 200 $\mathrm{kg} \mathrm{hm}^{-2}$, 分 3 次施用, 基肥、拔节期追肥和吐丝期追肥比 例为 $3: 4: 3$; 钾肥 $\left(\mathrm{K}_{2} \mathrm{O}\right)$ 用量 $120 \mathrm{~kg} \mathrm{hm}^{-2}$, 分 2 次施用, 基肥、吐丝期追肥比例为 $1: 1$ 。肥料种类为尿素( $\mathrm{N} \mathrm{46 \% )、}$ 过磷酸钙 $\left(\mathrm{P}_{2} \mathrm{O}_{5} 12 \%\right)$ 、硫酸钾 $\left(\mathrm{K}_{2} \mathrm{O} 53 \%\right)$ 。供试甜玉米品 种为先甜 5 号, 种植密度为 52,500 株 $\mathrm{hm}^{-2}$ 。甜玉米用穴 盘播种育苗后移栽, 全生育期均按当地高产田间管理方 式进行。甜玉米分别于 2018 年 3 月 28 日播种, 2018 年 6 月 13 日收获; 2019 年 3 月 28 日播种, 2019 年 6 月 29 日收
获。

1.3 样品采集及测

甜玉米拔节期于每个小区中取长势一致的代表性植 株 12 株; 吐丝期于每个小区中取长势一致的代表性植株 6 株, 植株按茎、叶(含叶鞘)、雄穗分别取样, 各器官样品 分别混合成混合样; 鲜食期于每个小区中取长势一致植 株 4 株, 植株按茎、叶(含叶鞘)、苞叶、籽粒、穗轴、雄 穗分别取样, 各器官样品分别混合成混合样。样品于 $105^{\circ} \mathrm{C}$ 杀青 $30 \mathrm{~min}, 80^{\circ} \mathrm{C}$ 烘干至恒重后称其干重, 各器官 磷浓度采用钒钼黄比色法测定 ${ }^{[19]}$ 。甜玉米鲜食期(吐丝后 $25 \mathrm{~d}$ 左右)每小区中间 3 行, 连续各收 10 株穗数, 共 30 株, 将其带苞叶鲜穗称重, 折算出各处理每公顷鲜穗产量。

\section{4 数据分析及相关计算}

植株磷素累积量 $\left(\mathrm{kg} \mathrm{hm}^{-2}\right)=$ 生物量 $\times$ 磷浓度 ${ }^{[20]}$ 
$1 \mathrm{~kg}$ 磷素生产鲜穗量 $\left(\mathrm{kg} \mathrm{kg}^{-1}\right)=$ 鲜食期鲜穗产量 $/$ 植 株地上部磷素累积量 ${ }^{[21]}$

磷素收获指数 $(\%)=$ 穗部磷素累积量/植株地上部磷 素累积量 $\times 100^{[20]}$

磷素生理效率 $\left(\mathrm{kg} \mathrm{kg}^{-1}\right)=$ 鲜食期生物量/植株地上部 磷素累积量 ${ }^{[22]}$

磷肥农学效率 $\left(\mathrm{kg} \mathrm{kg}^{-1}\right)=($ 施磷区甜玉米鲜穗产量一不 施磷区甜玉米鲜穗产量)/磷肥供应量 ${ }^{[23]}$

磷肥利用率 $(\%)=($ 施磷区植株地上部磷素累积量-不 施磷区植株地上部磷素累积量 $) /$ 磷肥供应量 $\times 100^{[23]}$

磷肥偏生产力 $\left(\mathrm{kg} \mathrm{kg}^{-1}\right)=$ 施磷区甜玉米鲜穗产量/磷 肥供应量 ${ }^{[24]}$

营养器官磷素转运量 $\left(\mathrm{kg} \mathrm{hm}^{-2}\right)=$ 吐丝期营养器官磷 素累积量一鲜食期营养器官磷素累积量 ${ }^{[20]}$

磷素转运对穗部的贡献率 $(\%)=$ 营养器官磷素转运 量/鲜食期穗部磷素累积量 $\times 100^{[21]}$

磷素转运效率 $(\%)=$ 营养器官磷素转运量/吐丝期营 养器官磷素累积量 $\times 100^{[20]}$

花后磷素同化量 $\left(\mathrm{kg} \mathrm{hm}^{-2}\right)=$ 鲜食期穗部磷素累积量一

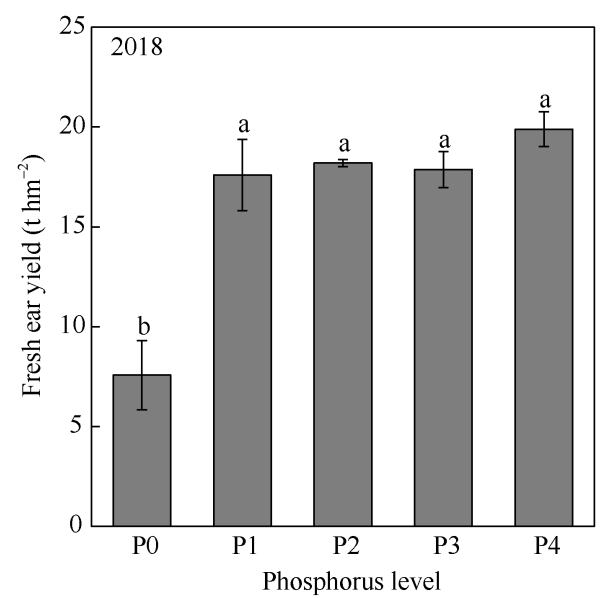

\section{营养器官磷素转运量 ${ }^{[21]}$}

采用 Microsoft Excel 2010 软件进行数据处理, 用 SPSS 23.0 软件进行数据统计和方差分析, 不同处理间 数据的多重比较采用 Duncan's 新复极差法检验 $(P<$ 0.05); 利用 Microsoft Excel 2010、SigmaPlot 12.5 软件 作图。

\section{2 结果与分析}

\section{1 磷肥供应对甜玉米鲜穗产量的影响}

2018 年和 2019 年, 磷肥供应均显著提高甜玉米鲜穗 产量。施磷处理 $(\mathrm{P} 1 \sim \mathrm{P} 4)$ 较不施磷处理 $(\mathrm{P} 0)$ 分别增产 $132.5 \% \sim 162.8 \%$ 、 $42.8 \% \sim 50.7 \%$; 但是不同施磷处理 (P1 P4)之间的产量差异不显著(图 2)。可见 $37.5 \mathrm{~kg} \mathrm{hm}^{-2}$ 磷肥供应量即可达到甜玉米最优产量。

\section{2 磷肥供应对甜玉米生物量和磷素累积动态的影响}

磷肥供应显著提高拔节期、吐丝期和鲜食期的甜玉米 植株生物量。2018 年鲜食期施磷处理(P1 P4)较不施磷处 理 (P0) 提高 $35.35 \%$ 38.93\%，2019 年鲜食期提高 $40.82 \% \sim 60.20 \%$ (表 1 )。

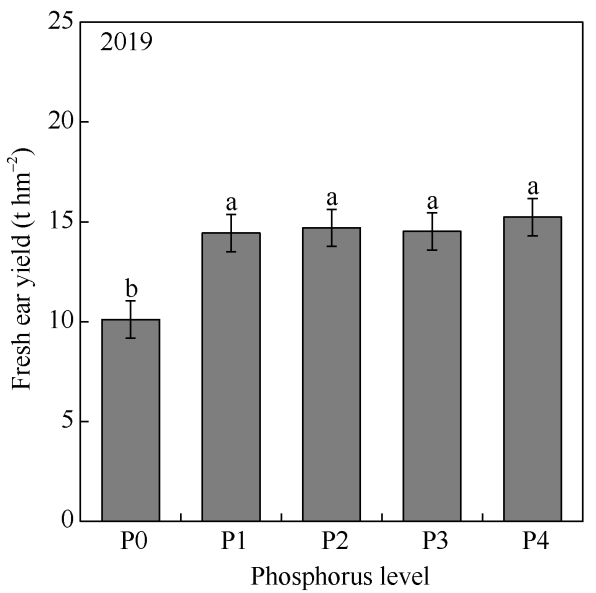

图 2 甜玉米鲜穗产量与施磷量的关系

Fig. 2 Relationships between $\mathrm{P}\left(\mathrm{P}_{2} \mathrm{O}_{5}\right)$ rates and fresh ear yield

图柱上不同小写字母表示不同处理间差异显著 $(P<0.05)$ 。 $0 、 \mathrm{P} 1 、 \mathrm{P} 2 、 \mathrm{P} 3 、 \mathrm{P} 4$ 分别表示磷肥供应 $0 、 37.5 、 75 、 150$ 和 $300 \mathrm{~kg}$ hm ${ }^{-2}$ 。 Values marked with different lowercase letters above the bars denote significant difference at $P<0.05$. P0, P1, P2, P3, and P4 mean different $P$ rates as $0,37.5,75,150$, and $300 \mathrm{~kg} \mathrm{hm}^{-2}$, respectively.

表 1 不同磷肥供应量下甜玉米各主要生育期植株生物量累积

Table 1 Dry matter mass of major growth stages under different $P$ rates in sweet corn

\begin{tabular}{|c|c|c|c|c|c|c|}
\hline \multirow{2}{*}{$\begin{array}{c}\text { 处理 } \\
\text { Treatment }\end{array}$} & \multicolumn{3}{|c|}{2018} & \multicolumn{3}{|c|}{2019} \\
\hline & $\begin{array}{c}\text { 拔节期 } \\
\text { Jointing stage }\end{array}$ & $\begin{array}{c}\text { 吐丝期 } \\
\text { Silking stage }\end{array}$ & $\begin{array}{c}\text { 鲜食期 } \\
\text { Fresh eating stage }\end{array}$ & $\begin{array}{c}\text { 拔节期 } \\
\text { Jointing stage }\end{array}$ & $\begin{array}{c}\text { 吐丝期 } \\
\text { Silking stage }\end{array}$ & $\begin{array}{c}\text { 鲜食期 } \\
\text { Fresh eating stage }\end{array}$ \\
\hline P0 & $0.21 \mathrm{c}$ & $2.29 \mathrm{~b}$ & $7.27 \mathrm{~b}$ & $0.28 \mathrm{~b}$ & $2.20 \mathrm{c}$ & $5.88 \mathrm{c}$ \\
\hline $\mathrm{P} 1$ & $0.39 \mathrm{~b}$ & $3.74 \mathrm{a}$ & $9.84 \mathrm{a}$ & $0.42 \mathrm{ab}$ & $3.49 \mathrm{~b}$ & $8.28 \mathrm{~b}$ \\
\hline P2 & $0.49 \mathrm{a}$ & $4.10 \mathrm{a}$ & $10.02 \mathrm{a}$ & $0.45 \mathrm{ab}$ & $3.72 \mathrm{~b}$ & $8.71 \mathrm{ab}$ \\
\hline P3 & $0.51 \mathrm{a}$ & $4.02 \mathrm{a}$ & $10.05 \mathrm{a}$ & $0.48 \mathrm{a}$ & $3.61 \mathrm{~b}$ & $8.83 \mathrm{ab}$ \\
\hline P4 & $0.52 \mathrm{a}$ & $4.30 \mathrm{a}$ & $10.10 \mathrm{a}$ & $0.49 \mathrm{a}$ & $4.36 \mathrm{a}$ & $9.42 \mathrm{a}$ \\
\hline
\end{tabular}

处理同图 2。同列数据后不同小写字母表示在 $P<0.05$ 水平差异显著。

Treatments are the same as those given in Fig. 2. Values followed by different lowercase letters within the same column indicate sign ificantly different at $P<0.05$. 
在拔节期、吐丝期和鲜食期甜玉米磷素累积上, 施磷 处理显著提高甜玉米植株磷素累积量, 其中 2018 年甜玉 米植株磷素累积量施磷处理较不施磷处理分别提高 $108.75 \%$ 222.67\%、96.23\% 124.93\%和 148.83\% 215.86\%; 2019 年甜玉米植株磷素累积量施磷处理较不施磷处理分 别提高 $64.47 \% \sim 123.68 \%$ 、85.27\% 200.45\%和 $105.81 \%$ $172.73 \%$ (图 3)。
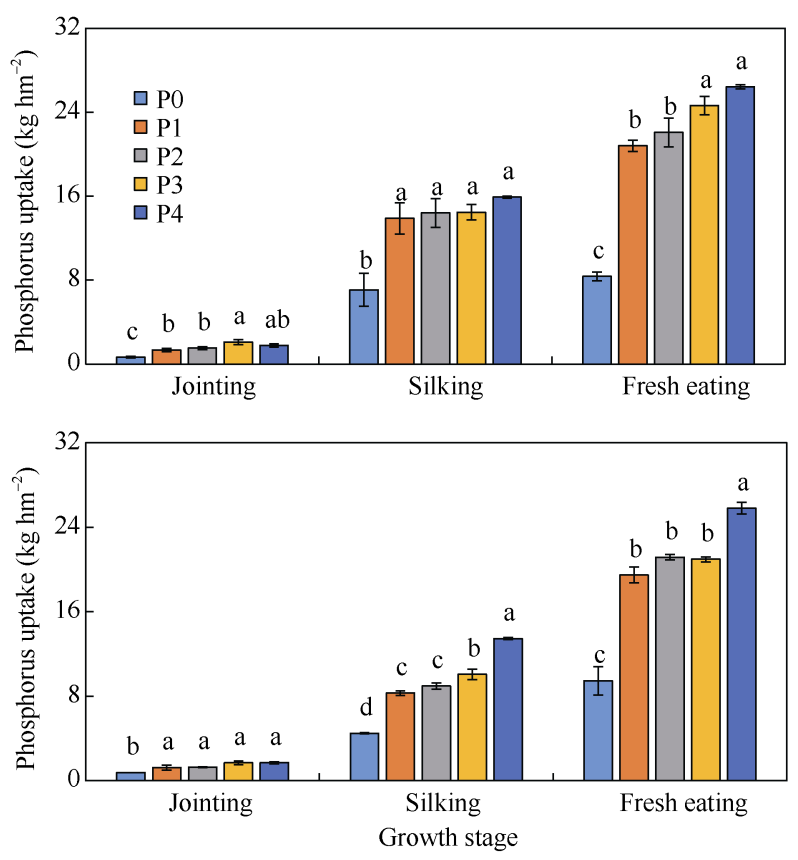

图 3 不同磷肥供应量下甜玉米各主要生育期植株磷素累积

Fig. 3 Phosphorus uptake of major growth stages under different $P$ rates in sweet corn

处理同图 2。图柱上不同小写字母表示不同处理间差异显著 $(P<$ $0.05)$ 。

Treatments are the same as those given in Fig. 2. Values marked with different lowercase letters are significantly different among treatments at $P<0.05$.

\section{3 磷肥供应对甜玉米鲜食期磷素累积分配影响}

磷肥供应可以显著提高 2018 年和 2019 年鲜食期甜玉 米茎、叶(含叶鞘)、苞叶、穗轴和籽粒的生物量(2019 年 茎除外), 但是施磷处理(P1 P4)之间的各器官生物量差异 不显著(表 2)。磷肥供应后甜玉米鲜食期各器官磷浓度较 不施磷处理(P0)均有所上升, 其中 2018 年甜玉米施磷处 理下的茎磷浓度较不施磷处理提高 $125.00 \%$ 375.00\%, 2019 年提高 $200.00 \%$ 320.00\%；2018 年甜玉米施磷处理 下的苍叶的磷浓度较不施磷处理提高 $120.00 \%$ 360.00\%, 2019 年提高 $128.57 \%$ 228.57\% (表 3)。此外，磷肥供应显 著增加甜玉米籽粒磷浓度，但是施磷处理之间差异不显 著。磷肥供应对甜玉米鲜食期植株磷素累积和分配有显著 影响, 不同处理间各器官磷素累积量分配比例大致表现 为籽粒 $>$ 叶 (含叶鞘) $>$ 茎 $>$ 穗轴 $>$ 苞叶 > 雄穗 (图 4)。2 年间甜玉米的籽粒磷素累积分别占植株累积的 $42.08 \%$ 和 $42.09 \%$, 这主要是因为籽粒中磷浓度较高; 而且施磷显著增 加籽粒磷累积量, 但是施磷处理之间差异不大。

2.4 磷肥供应对甜玉米磷素转运的影响

2018年甜玉米对鲜穗磷素的贡献率表现为: 花后磷 同化 $>$ 叶(含叶鞘)转运 $>$ 茎转运 $>$ 雄穗转运, 各处理平均值 分别为 $61.54 \% 、 33.98 \% 、 2.83 \%$ 和 $1.65 \%$ (表 4$)$ 。磷肥供应 可以增加花后磷同化对鲜穗磷素的贡献率，在 $\mathrm{P} 4$ 处理达 到最高 $(80.98 \%)$; 但是叶(含叶鞘)、雄穗磷转运对鲜穗磷 素的贡献率则随着磷肥供应量的增加而降低。2019年甜玉 米各处理对鲜穗磷素的贡献率最大，也是花后磷同化(表 4), 花后磷同化对鲜穗磷素的贡献率在 P0 处理最低 (74.53\%), P1处理达到最高(93.05\%)。

\section{5 磷肥供应对甜玉米磷素利用效率的影响}

磷肥供应量对 $1 \mathrm{~kg}$ 磷素生产鲜穗量、磷素生理效率有 显著性影响, 随着磷肥供应量的增加而显著降低, 不施磷 处理 $(\mathrm{P} 0)$ 与施磷处理 $(\mathrm{P} 1 \sim \mathrm{P} 4)$ 之间的磷素生理效率有存在

表 2 不同磷肥供应量下甜玉米鲜食期各器官生物量

Table 2 Biomass of various organs at fresh ear stage under different $\mathrm{P}\left(\mathrm{P}_{2} \mathrm{O}_{5}\right)$ rates in sweet corn

\begin{tabular}{|c|c|c|c|c|c|c|c|}
\hline 年份 & 处理 & 茎 & 叶(含叶鞘) & 苞叶 & 籽粒 & $\begin{array}{l}\text { 穗轴 } \\
\end{array}$ & 雄穗 \\
\hline Year & Treatment & Stem & Blade (including sheath) & Bract & Grain & $\mathrm{Cob}$ & Tassel \\
\hline \multirow[t]{5}{*}{2018} & P0 & $1.44 \mathrm{~b}$ & $2.74 \mathrm{~b}$ & $0.83 \mathrm{~b}$ & $1.06 \mathrm{~b}$ & $0.68 \mathrm{~b}$ & $0.53 \mathrm{~b}$ \\
\hline & P1 & $1.58 \mathrm{a}$ & $3.24 \mathrm{a}$ & $1.14 \mathrm{a}$ & $2.17 \mathrm{a}$ & $1.17 \mathrm{a}$ & $0.55 \mathrm{ab}$ \\
\hline & $\mathrm{P} 2$ & $1.63 \mathrm{a}$ & $3.32 \mathrm{a}$ & $1.22 \mathrm{a}$ & $2.12 \mathrm{a}$ & $1.19 \mathrm{a}$ & $0.53 \mathrm{~b}$ \\
\hline & P3 & $1.56 \mathrm{ab}$ & $3.35 \mathrm{a}$ & $1.16 \mathrm{a}$ & $2.15 \mathrm{a}$ & $1.28 \mathrm{a}$ & $0.55 \mathrm{ab}$ \\
\hline & P4 & $1.57 \mathrm{ab}$ & $3.45 \mathrm{a}$ & $1.13 \mathrm{a}$ & $2.16 \mathrm{a}$ & $1.20 \mathrm{a}$ & $0.57 \mathrm{a}$ \\
\hline \multirow[t]{5}{*}{2019} & $\mathrm{P} 0$ & $1.13 \mathrm{~b}$ & $1.85 \mathrm{~b}$ & $0.61 \mathrm{~b}$ & $1.20 \mathrm{~b}$ & $0.63 \mathrm{~b}$ & $0.47 \mathrm{a}$ \\
\hline & $\mathrm{P} 1$ & $1.29 \mathrm{ab}$ & $2.93 \mathrm{a}$ & $1.00 \mathrm{a}$ & $1.73 \mathrm{a}$ & $0.85 \mathrm{a}$ & $0.48 \mathrm{a}$ \\
\hline & $\mathrm{P} 2$ & $1.23 \mathrm{~b}$ & $3.04 \mathrm{a}$ & $1.15 \mathrm{a}$ & $1.89 \mathrm{a}$ & $0.93 \mathrm{a}$ & $0.47 \mathrm{a}$ \\
\hline & P3 & $1.13 \mathrm{~b}$ & $3.46 \mathrm{a}$ & $1.03 \mathrm{a}$ & $1.79 \mathrm{a}$ & $0.94 \mathrm{a}$ & $0.48 \mathrm{a}$ \\
\hline & P4 & $1.43 \mathrm{a}$ & $3.49 \mathrm{a}$ & $1.14 \mathrm{a}$ & $1.91 \mathrm{a}$ & $0.96 \mathrm{a}$ & $0.49 \mathrm{a}$ \\
\hline
\end{tabular}

处理同图 2。标以不同小写字母的值在同一年不同处理间 $P<0.05$ 水平差异显著。

Treatments are the same as those given in Fig. 2. Values followed by different lowercase letters are significantly different at $P<0.05$ among different treatments. 
表 3 不同磷肥供应量下甜玉米鲜食期各器官磷浓度

Table $3 \quad P\left(P_{2} O_{5}\right)$ concentration of various organs at fresh ear stage under different $P$ rates in sweet corn

\begin{tabular}{|c|c|c|c|c|c|c|c|}
\hline 年份 & 处理 & 茎 & 叶(含叶鞘) & 苞叶 & 籽粒 & $\begin{array}{l}\text { 穗轴 } \\
\end{array}$ & $\begin{array}{l}\text { 雄穗 } \\
\end{array}$ \\
\hline Year & Treatment & Stem & Blade (including sheath) & Bract & Grain & $\mathrm{Cob}$ & Tassel \\
\hline \multirow[t]{5}{*}{2018} & P0 & $0.04 \mathrm{~d}$ & $0.10 \mathrm{c}$ & $0.05 \mathrm{~d}$ & $0.30 \mathrm{~b}$ & $0.17 \mathrm{a}$ & $0.05 \mathrm{~d}$ \\
\hline & $\mathrm{P} 1$ & $0.09 \mathrm{c}$ & $0.19 \mathrm{~b}$ & $0.11 \mathrm{c}$ & $0.45 \mathrm{a}$ & $0.15 \mathrm{a}$ & $0.09 \mathrm{c}$ \\
\hline & P2 & $0.14 \mathrm{~b}$ & $0.20 \mathrm{ab}$ & $0.15 b c$ & $0.43 \mathrm{a}$ & $0.15 \mathrm{a}$ & $0.09 \mathrm{c}$ \\
\hline & P3 & $0.15 \mathrm{~b}$ & $0.20 \mathrm{ab}$ & $0.20 \mathrm{ab}$ & $0.50 \mathrm{a}$ & $0.17 \mathrm{a}$ & $0.10 \mathrm{~b}$ \\
\hline & P4 & $0.19 \mathrm{a}$ & $0.23 \mathrm{a}$ & $0.23 \mathrm{a}$ & $0.48 \mathrm{a}$ & $0.17 \mathrm{a}$ & $0.12 \mathrm{a}$ \\
\hline \multirow[t]{5}{*}{2019} & $\mathrm{P} 0$ & $0.05 \mathrm{c}$ & $0.12 \mathrm{~b}$ & $0.07 \mathrm{c}$ & $0.42 \mathrm{~b}$ & $0.16 \mathrm{c}$ & $0.08 \mathrm{c}$ \\
\hline & P1 & $0.15 \mathrm{~b}$ & $0.18 \mathrm{ab}$ & $0.16 \mathrm{~b}$ & $0.50 \mathrm{a}$ & $0.20 \mathrm{bc}$ & $0.09 \mathrm{bc}$ \\
\hline & P2 & $0.17 \mathrm{ab}$ & $0.18 \mathrm{ab}$ & $0.17 \mathrm{ab}$ & $0.48 \mathrm{ab}$ & $0.23 \mathrm{ab}$ & $0.11 \mathrm{ab}$ \\
\hline & P3 & $0.19 \mathrm{ab}$ & $0.17 \mathrm{ab}$ & $0.19 \mathrm{ab}$ & $0.48 \mathrm{ab}$ & $0.25 \mathrm{ab}$ & $0.09 \mathrm{cbc}$ \\
\hline & P4 & $0.21 \mathrm{a}$ & $0.22 \mathrm{a}$ & $0.23 \mathrm{a}$ & $0.49 \mathrm{ab}$ & $0.27 \mathrm{a}$ & $0.13 \mathrm{a}$ \\
\hline
\end{tabular}

处理同图 2。标以不同小写字母的值在同一年不同处理间 $P<0.05$ 水平差异显著。

Treatments are the same as those given in Fig. 2. Values followed by different lowercase letters are significantly different at $P<0.05$ among different treatments.
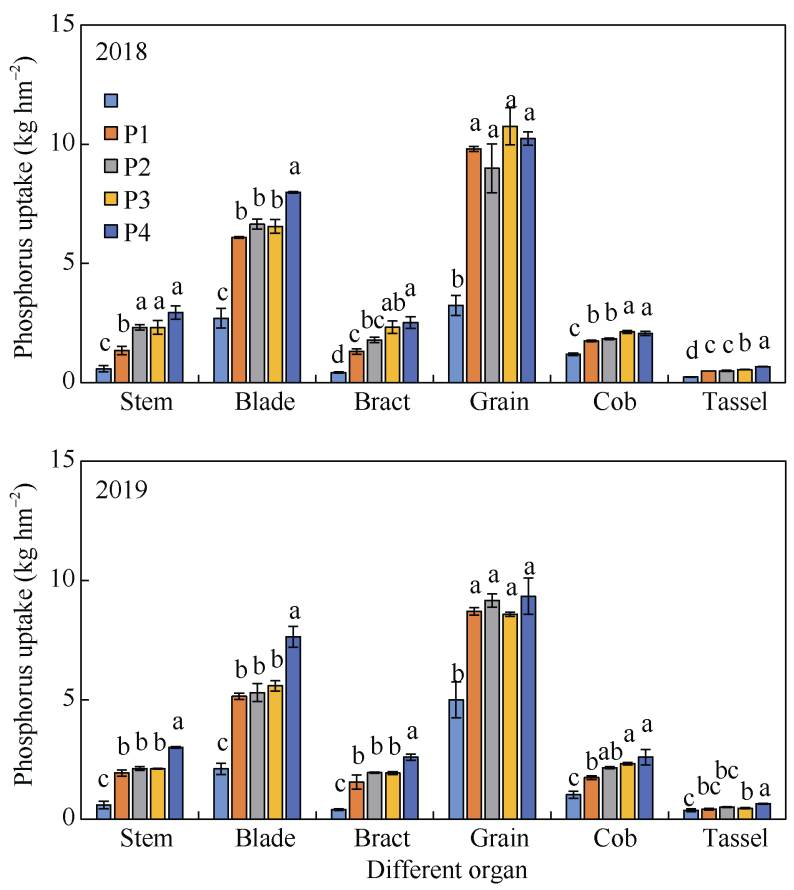

图 4 不同磷肥供应量下甜玉米鲜食期磷素累积分配

Fig. 4 P uptake of different organs at the fresh ear stage under different $P$ rates in sweet corn

处理同图 2。图柱上小写字母不同表示不同处理间差异显著 $(P<$ $0.05)$ 。

Treatments are the same as those given in Fig. 2. Values marked with different lowercase letters are significantly different among treatments at $P<0.05$.

显著差异，而施磷处理之间并无显著性差异。2018-2019 两年甜玉米磷素收获指数分别在 P1 和 P0 处理达到最高, 分别为 $57.93 \%$ 和 $67.63 \%$, 磷素收获指数在处理间存在显 著性差异。磷肥农学效率、回收利用率和偏生产力均随着 磷肥供应量增加而明显下降, 其中 2018 年甜玉米的磷肥
利用率从 P1 处理 $74.24 \%$ 下降到 P4 处理 13.56\%, 2019 年 甜玉米的磷肥利用率从 P1 处理 $61.11 \%$ 下降到 P4 处理 $12.47 \%$ ，两季趋势基本一致(表 5)。

\section{3 讨论}

磷肥的合理供应是调控作物生长发育与产量形成的 重要措施 ${ }^{[25]}$ 。江帆等 ${ }^{[26]}$ 研究表明玉米产量随着磷肥供应 量增加而显著增加，但超过一定范围 $\left(140 \mathrm{~kg} \mathrm{hm}^{-2}\right)$ 也会 导致玉米减产 ${ }^{[27]}$ 。在北方普通玉米主产区上磷肥 $\left(\mathrm{P}_{2} \mathrm{O}_{5}\right)$ 平 均推荐量为 $84 \mathrm{~kg} \mathrm{hm}^{-2}[15]$, 而华南区甜玉米种植中磷肥 $\left(\mathrm{P}_{2} \mathrm{O}_{5}\right)$ 推荐量高达 $105 \mathrm{~kg} \mathrm{hm}^{-2}{ }^{[28]}$ 。但本研究结果表明磷 肥供应量 $\left(\mathrm{P}_{2} \mathrm{O}_{5}\right)$ 于 $37.5 \mathrm{~kg} \mathrm{hm}^{-2}$ 后甜玉米产量即不再显著 增加, 甜玉米在达高产目标的条件下磷肥需求量远低于 前人研究结果。这可能是以往研究中磷肥多进行撒施, 而 本研究磷肥是近距离集中施用(穴施)。磷肥穴施可增加磷 素与甜玉米根系的接触，促进根系吸收磷肥，同时减少磷 肥被土壤固定沉淀风险 ${ }^{[29]}$ ，从而提高磷肥的利用效率。此 外, 本研究土壤类型为赤红壤中的赤砂土土属, 沙质土壤 对磷素吸附能力较弱, 磷肥不易被土壤吸附, 可以更好地 转化为速效磷被作物吸收利用 ${ }^{[30]}$ 。因此, 在本试验条件下, 甜玉米磷肥梯度试验结果表明 $37.5 \mathrm{~kg} \mathrm{hm}^{-2}$ 磷肥穴施即可 保障甜玉米稳产需求，而且 2 年平均磷肥利用率高达 $67.7 \%$ 。

生物量累积是作物生长发育的前提, 而明确磷素的 累积动态是科学施用磷肥的基础。本研究甜玉米植株生物 量随生育期的推进逐渐增加，而且磷肥供应显著提高甜 玉米鲜食期生物量, 这与前人研究结果一致 ${ }^{[31-32]}$ 。磷肥供 应显著提高甜玉米植株的磷素累积量, 其中鲜食期籽粒 磷素累积量约占植株磷素累积量的 $42 \%$ ，远低于普通

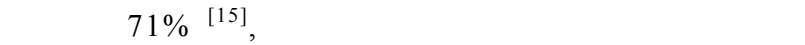
(P1 P4)之间并无显著性差异, 可能是大量的磷素供应营 
表 4 开花后营养器官中磷素向穗部的转移量及贡献率

Table 4 P translocation amount and contribution proportion from vegetative organs to ear after the anthesis

\begin{tabular}{|c|c|c|c|c|c|c|c|c|c|}
\hline \multirow{2}{*}{$\begin{array}{l}\text { 年份 } \\
\text { Year }\end{array}$} & \multirow{2}{*}{$\begin{array}{c}\text { 处理 } \\
\text { Treatment }\end{array}$} & \multirow{2}{*}{$\begin{array}{l}\text { 花后磷同 } \\
\text { 化量 } \\
\text { AAAAp } \\
\left(\mathrm{kg} \mathrm{hm}^{-2}\right) \\
\end{array}$} & \multirow{2}{*}{$\begin{array}{c}\text { 茎磷转 } \\
\text { 运量 } \\
\text { TAFSp } \\
\left(\mathrm{kg} \mathrm{hm}^{-2}\right) \\
\end{array}$} & \multirow{2}{*}{$\begin{array}{c}\text { 叶(含叶鞘)磷 } \\
\text { 转运量 } \\
\text { TAFBSp } \\
\left(\mathrm{kg} \mathrm{hm}^{-2}\right)\end{array}$} & \multirow{2}{*}{$\begin{array}{c}\text { 雄穗磷转 } \\
\text { 运量 } \\
\text { TAFTp } \\
\left(\mathrm{kg} \mathrm{hm}^{-2}\right) \\
\end{array}$} & \multicolumn{4}{|c|}{ 磷素转运对穗部的贡献率 CFE (\%) } \\
\hline & & & & & & AAAAp & TAFSp & TAFBSp & TAFTp \\
\hline \multirow[t]{5}{*}{2018} & P0 & $1.29 \mathrm{~b}$ & $0.62 \mathrm{ab}$ & $2.35 \mathrm{a}$ & $0.40 \mathrm{a}$ & $31.13 \mathrm{~b}$ & $13.41 \mathrm{a}$ & $47.00 \mathrm{a}$ & $8.46 \mathrm{a}$ \\
\hline & P1 & $6.93 \mathrm{a}$ & $0.75 \mathrm{a}$ & $3.89 \mathrm{a}$ & $0.48 \mathrm{a}$ & $57.33 \mathrm{ab}$ & $6.23 \mathrm{~b}$ & $32.43 \mathrm{ab}$ & $4.00 \mathrm{~b}$ \\
\hline & $\mathrm{P} 2$ & $7.13 \mathrm{a}$ & $-0.16 \mathrm{~b}$ & $4.38 \mathrm{a}$ & $-0.01 \mathrm{ab}$ & $62.34 \mathrm{ab}$ & $-1.07 \mathrm{c}$ & $38.75 \mathrm{a}$ & $-0.01 \mathrm{c}$ \\
\hline & P3 & 10.17 a & $-0.29 \mathrm{~b}$ & $4.03 \mathrm{a}$ & $-0.47 \mathrm{~b}$ & $75.92 \mathrm{ab}$ & $-2.41 \mathrm{c}$ & $29.86 \mathrm{a}$ & $-3.36 \mathrm{c}$ \\
\hline & P4 & $10.51 \mathrm{a}$ & $-0.26 \mathrm{~b}$ & $2.83 \mathrm{a}$ & $-0.11 b$ & 80.98 a & $-2.03 \mathrm{c}$ & $21.87 \mathrm{a}$ & $-0.82 \mathrm{c}$ \\
\hline \multirow[t]{5}{*}{2019} & $\mathrm{P} 0$ & $4.98 \mathrm{~b}$ & $0.02 \mathrm{a}$ & $1.02 \mathrm{a}$ & $0.38 \mathrm{c}$ & $74.53 \mathrm{~b}$ & $1.11 \mathrm{a}$ & $17.29 \mathrm{a}$ & $7.06 \mathrm{a}$ \\
\hline & P1 & $11.16 \mathrm{a}$ & $-0.35 \mathrm{a}$ & $-0.01 \mathrm{c}$ & $1.18 \mathrm{~b}$ & $93.05 \mathrm{a}$ & $-2.89 \mathrm{a}$ & $-0.15 b$ & $9.99 \mathrm{a}$ \\
\hline & $\mathrm{P} 2$ & $12.20 \mathrm{a}$ & $-0.35 \mathrm{a}$ & $0.19 \mathrm{bc}$ & $1.21 \mathrm{ab}$ & $92.06 \mathrm{ab}$ & $-2.59 \mathrm{a}$ & $1.38 \mathrm{~b}$ & $9.15 \mathrm{a}$ \\
\hline & P3 & $10.90 \mathrm{a}$ & $-0.18 \mathrm{a}$ & $0.86 \mathrm{ab}$ & $1.25 \mathrm{ab}$ & $84.95 \mathrm{ab}$ & $-1.41 \mathrm{a}$ & $6.72 \mathrm{~b}$ & $9.75 \mathrm{a}$ \\
\hline & P4 & $12.33 \mathrm{a}$ & $-0.16 \mathrm{a}$ & $0.66 \mathrm{abc}$ & $1.69 \mathrm{a}$ & $84.98 \mathrm{ab}$ & $-1.11 \mathrm{a}$ & $4.43 \mathrm{~b}$ & $11.70 \mathrm{a}$ \\
\hline
\end{tabular}

处理同图 2。标以不同小写字母的值在同一年不同处理间 $P<0.05$ 水平差异显著。

CFE means contribution to fresh ear; AAAAp means P assimilating amount after anthesis; TAFSp means P translocation amount from stem; TAFBSp means P translocation amount from brade and sheath; TAFTp means P translocation amount from tassel. Treatments are the same as those given in Fig. 2. Values followed by different lowercase letters are significantly different among different treatments at $P<0.05$.

表 5 不同磷肥供应量下甜玉米磷素效率的差异

Table 5 Difference of phosphorus use efficiencies under different $P$ rates in sweet corn

\begin{tabular}{|c|c|c|c|c|c|c|c|}
\hline $\begin{array}{l}\text { 年份 } \\
\text { Year }\end{array}$ & $\begin{array}{c}\text { 处理 } \\
\text { Treatment }\end{array}$ & $\begin{array}{c}\mathrm{kg} \text { 磷素产鲜穗量 } \\
\text { Yield per } \\
\text { phosphorus } \\
\text { accumulation } \\
\left(\mathrm{kg} \mathrm{kg}^{-1}\right) \\
\end{array}$ & $\begin{array}{c}\text { 磷素生理效率 } \\
\text { Phosphorus } \\
\text { internal } \\
\text { efficiency } \\
\left(\mathrm{kg} \mathrm{kg}^{-1}\right) \\
\end{array}$ & $\begin{array}{c}\text { 磷素收获指数 } \\
\text { Phosphorus } \\
\text { harvest index } \\
(\%)\end{array}$ & $\begin{array}{c}\text { 磷肥农学效率 } \\
\text { Phosphorus } \\
\text { agronomic } \\
\text { efficiency } \\
\left(\mathrm{kg} \mathrm{kg}^{-1}\right) \\
\end{array}$ & $\begin{array}{l}\text { 磷肥利用率 } \\
\text { Phosphorus } \\
\text { recovery } \\
\text { efficiency } \\
(\%) \\
\end{array}$ & $\begin{array}{c}\text { 磷肥偏生产力 } \\
\text { Phosphorus } \\
\text { partial factor } \\
\text { productivity } \\
\left(\mathrm{kg} \mathrm{kg}^{-1}\right)\end{array}$ \\
\hline \multirow[t]{5}{*}{2018} & P0 & $897.29 a$ & $871.96 \mathrm{a}$ & $55.79 \mathrm{ab}$ & - & - & - \\
\hline & P1 & $845.86 \mathrm{a}$ & $472.88 \mathrm{~b}$ & $57.93 \mathrm{a}$ & $267.52 \mathrm{a}$ & $74.24 \mathrm{a}$ & $469.39 \mathrm{a}$ \\
\hline & P2 & $829.97 \mathrm{a}$ & $458.59 \mathrm{bc}$ & $51.13 \mathrm{bc}$ & $141.73 \mathrm{~b}$ & $41.02 \mathrm{~b}$ & $242.67 \mathrm{~b}$ \\
\hline & P3 & $725.46 \mathrm{a}$ & $408.45 \mathrm{bc}$ & $54.50 \mathrm{abc}$ & $68.63 \mathrm{bc}$ & $24.40 \mathrm{c}$ & $119.10 \mathrm{c}$ \\
\hline & P4 & $752.79 \mathrm{a}$ & $382.31 \mathrm{c}$ & $49.10 \mathrm{c}$ & $41.05 \mathrm{c}$ & $13.56 \mathrm{~d}$ & $66.28 \mathrm{c}$ \\
\hline \multirow[t]{5}{*}{2019} & $\mathrm{P} 0$ & $1124.13 \mathrm{a}$ & $641.26 \mathrm{a}$ & $67.63 \mathrm{a}$ & - & - & - \\
\hline & P1 & $744.76 \mathrm{~b}$ & $426.30 \mathrm{~b}$ & $61.54 \mathrm{~b}$ & $115.31 \mathrm{a}$ & $61.11 \mathrm{a}$ & $385.00 \mathrm{a}$ \\
\hline & $\mathrm{P} 2$ & $694.17 \mathrm{~b}$ & $411.69 \mathrm{~b}$ & $62.61 \mathrm{~b}$ & $61.15 \mathrm{~b}$ & $35.73 \mathrm{~b}$ & $196.00 \mathrm{~b}$ \\
\hline & P3 & $692.69 \mathrm{~b}$ & $421.39 \mathrm{~b}$ & $61.20 \mathrm{~b}$ & $29.41 \mathrm{bc}$ & $17.56 \mathrm{c}$ & $96.83 \mathrm{c}$ \\
\hline & P4 & $592.42 \mathrm{~b}$ & $365.35 \mathrm{~b}$ & $56.28 \mathrm{c}$ & $17.10 \mathrm{c}$ & $12.47 \mathrm{c}$ & $50.81 \mathrm{~d}$ \\
\hline
\end{tabular}

处理同图 2。标以不同小写字母的值在同一年不同处理间 $P<0.05$ 水平差异显著。

Treatments are the same as those given in Fig. 2. Values followed by different lowercase letters are significantly different among different treatments at $P<0.05$.

养体生长,存在磷素奢侈吸收现象，可见适宜的磷素供应 对于养分有效转移到籽粒中非常重要 ${ }^{[33]}$ 。普通玉米成熟期 磷素(P)累积量介于 46 95 $\mathrm{kg} \mathrm{hm}^{-2}$, 均值为 $73 \mathrm{~kg} \mathrm{hm}^{-2}[15]$, 但是本研究磷肥供应处理下 2 年间甜玉米鲜食期平均磷 素(P)累积量仅为 $22.7 \mathrm{~kg} \mathrm{hm}^{-2}$, 低于普通玉米的磷素累积 量。这一方面可能是因为我国甜玉米主产区华南地区的光 照资源相对不足 ${ }^{[34]}$, 加上甜玉米种植密度不高导致甜玉 米群体生物量较低从而影响其磷素累积量。此外, 与普通 玉米相比, 甜玉米于鲜食期(相当于普通玉米乳熟期, 在 吐丝后 $25 \mathrm{~d}$ 左右)采收, 收获期较普通玉米提前也是导致
甜玉米和普通玉米磷素植株磷素累积量差异的原因之

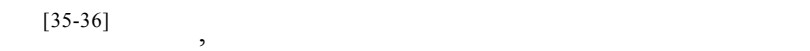
管理, 而应根据甜玉米植株磷素需求进行合理磷肥供应, 以提高磷肥利用率, 节约磷矿资源。

研究表明普通玉米花后营养体(茎、叶、雄穗)磷素向 穗部转运量大于其自身累积量 ${ }^{[18]}$, 其中叶片磷素转移率 最高 ${ }^{[37]}$ 。但是本研究发现在甜玉米穗部磷素累积来自营 养体(茎、叶、雄穗) 的转运较少, 绝大部分来自于花后同 化(P0 处理除外), 因此花后管理对甜玉米生物量和磷素 积累至关重要。甜玉米磷素生理效率、农学效率、利用率、 
偏生产力等是衡量合理施肥的重要指标, 均随着磷肥投 入增加显著下降, P1 处理 $\left(37.5 \mathrm{~kg} \mathrm{hm}^{-2}\right), 2$ 年甜玉米磷素 利用率均值高达 $67.7 \%$, 明显高于我国普通玉米 $(11.00 \%)^{[9]}$ 。 本研究条件下, 甜玉米磷肥合理的供应 $\left(37.5 \mathrm{~kg} \mathrm{hm}^{-2}\right)$ 能 有效地阻控农田磷素的损失, 减少磷肥向环境排放的风 险; 而且磷肥穴施促进甜玉米对磷素的吸收, 大大提高了 磷素利用率。

\section{References}

[1] 高否, 李余良, 李武, 俞婷, 李高科, 李春艳, 胡建广. 不同施 氮水平对南方甜玉米氮素吸收利用的影响. 植物营养与肥料 学报, 2017, 23: 1215-1224.

Gao L, Li Y L, Li W, Yu T, Li G K, Li C Y, Hu J G. Effects of nitrogen application on yields and nitrogen use efficiencies of sweet corn in south China. Plant Nutr Fert Sci, 2017, 23: 1215-1224 (in Chinese with English abstract).

[2]赵福成, 景立权, 问发宝, 陆大雷, 王桂跃, 陆卫平. 施氮量 对甜玉米产量、品质和蔗糖代谢酶活性的影响. 植物营养与肥 料学报, 2013, 19: 45-54.

Zhao F C, Jing L Q, Yan F B, Lu D L, Wang G Y, Lu W P. Effects of nitrogen fertilization on yield, quality and enzyme activity associated with sucrose metabolism of sweet corn. Plant Nutr Fert Sci, 2013, 19: 45-54 (in Chinese with English abstract).

[3] 陈建生, 徐培智, 唐拴虎, 张发宝, 解开治, 黄旭. 施肥对甜 玉米物质形成累积特征影响研究. 植物营养与肥料学报, 2010, 16: 58-64.

Chen J S, Xu P Z, Tang S H, Zhang F B, Xie K Z, Huang X. Effects of fertilization on cumulating characteristics of dried matter mass of sweet corn. Plant Nutr Fert Sci, 2010, 16: 58-64 (in Chinese with English abstract).

[4] 曾晓花, 万忠, 尹艳, 胡建广. 2011 年广东甜玉米产业发展现 状分析. 广东农业科学, 2012, (3): 12-14.

Zeng X H, Wan Z, Yin Y, Hu J G. Analysis the development status of sweet corn industry in Guangdong in 2011. Guangdong Agric Sci, 2012, (3): 12-14 (in Chinese with English abstract).

[5] 苗淑杰, 乔云发, 韩晓增, 王树起, 李海波. 缺磷对已结瘤大 豆生长和固氮功能的影响. 作物学报, 2009, 35: 1344-1349. Miao S J, Qiao Y F, Han X Z, Wang S Q, Li H B. Effects of phosphorus deficiency on growth and nitrogen fixation of soybean after nodule formation. Acta Agron Sin, 2009, 35: 1344-1349 (in Chinese with English abstract).

[6] 陈远学, 李汉邯, 周涛, 陈新平, 黄蔚, 刘静, 张朝春, 徐开未. 施磷对间套作玉米叶面积指数、干物质积累分配及磷肥利用 效率的影响. 应用生态学报, 2013, 24: 2799-2806.

Chen Y X, Li H H, Zhou T, Chen X P, Huang W, Liu J, Zhang C $\mathrm{C}, \mathrm{Xu} \mathrm{K} \mathrm{W.} \mathrm{Effects} \mathrm{of} \mathrm{phosphorus} \mathrm{fertilization} \mathrm{on} \mathrm{leaf} \mathrm{area} \mathrm{index,}$ biomass accumulation and allocation, and phosphorus use efficiency of intercropped maize. Chin J Appl Ecol, 2013, 24: 2799-2806 (in Chinese with English abstract).

[7] Vance C P, Uhde-Stone C, Allan D L. Phosphorus acquisition and use: critical adaptations by plants for securing a nonrenewable resource. New Phytol, 2010, 157: 423-447.

[8] 李杰, 石元亮, 陈智文. 我国南方红壤磷素研究概况. 土壤通 报, 2011, 42: 763-768.
Li J, Shi Y L, Chen Z W. Study on phosphorus in red soil in southern China. Chin J Soil Sci, 2011, 42: 763-768 (in Chinese with English abstract).

[9] 张福锁, 王激清, 张卫峰, 崔振岭, 马文奇, 陈新平, 江荣风. 中国主要粮食作物肥料利用率现状与提高途径. 土壤学报, 2008, 45: 915-924.

Zhang F S, Wang J Q, Zhang W F, Cui Z L, Ma W Q, Chen X P, Jiang R F. Nutrient use efficiencies of major cereal in China and measures for improvement. Acta Pedol Sin, 2008, 45: 915-924 (in Chinese with English abstract).

[10] Li H, Huang G, Meng Q, Ma L, Yuan L, Wang F, Jiang R. Integrated soil and plant phosphorus management for corn and environment in China: a review. Plant Soil, 2011, 349: 157-167.

[11] He P, Li S, Jin J, Wang H, Li C, Wang Y, Cui R. Performance of an optimized nutrient management system for double-cropped wheat-maize rotations in North-Central China. Agron J, 2009, 101: 1489-1496.

[12] 姚锦秋, 范富, 葛海峰, 张庆国, 侯迷红, 何凤艳, 李晓东. 施 肥对玉米产量构成因素的影响. 内蒙古民族大学学报(自然科 学版), 2010, 25: 648-652.

Yao J Q, Fan F, Ge H F, Zhang Q G, Hou M H, He F Y, Li X D. Effect of fertilization on yield traits in maize. $J$ Inner Mongolia Univ Nation (Nat Sci), 2010, 25: 648-652 (in Chinese with English abstract).

[13] 李川, 乔江方, 朱卫红, 黄璐, 代书桃, 刘京宝. 不同磷肥处 理对夏玉米干物质积累量及磷素吸收量的影响. 江苏农业科 学, 2019, 47(12): 107-113.

Li C, Qiao J F, Zhu W H, Huang L, Dai S T, Liu J B. Effects of different phosphate treatments on dry matter accumulation and phosphorus uptake in summer maize. J Jiangsu Agric Sci, 2019, 47(12): 107-113 (in Chinese with English abstract).

[14] 李文娟, 何萍, 金继运. 钾素营养对玉米生育后期干物质和养 分积累与转运的影响. 植物营养与肥料学报, 2009, 15: 799-807.

Li W J, He P, Jin J Y. Potassium nutrition on dry matter and nutrients accumulation and translocation at reproductive stage of maize. Plant Nutr Fert Sci, 2009, 15: 799-807 (in Chinese with English abstract).

[15] Wu L, Cui Z, Chen X, Yue S, Sun Y, Zhao R, Chen K. Change in phosphorus requirement with increasing grain yield for Chinese maize production. Field Crops Res, 2015, 180: 216-220.

[16] 肖春华, 李少昆, 刘景德, 王文静, 宋秋生. 种植方式对玉米 养分吸收动态和利用效率的影响. 中国土壤与肥料, 2005, (2): $10-13$.

Xiao C H, Li S K, Liu J D, Wang W J, Song Q S. Study on the dynamics of dry matter and nutrient accumulation in maize under various planting systems. Soil Fert Sci China, 2005, (2): 10-13 (in Chinese with English abstract).

[17] 吕新, 张伟, 胡昌浩, 董树亭, 白萍. 玉米种植区气候生态因 素优势综合评价研究. 干旱区研究, 2005, 22: 387-390.

Lyu X, Zhang W, Hu C H, Dong S T, Bai P. Study on the integrated evaluation of the advantages of climatic ecological factors in maize-growing regions. Arid Zone Res, 2005, 22: 387-390 (in Chinese with English abstract).

[18] 高伟, 金继运, 何萍, 李叔田. 我国北方不同地区玉米养分吸 收及累积动态研究. 植物营养与肥料学报, 2008, 14: 623-629. Gao W, Jin J Y, He P, Li S T. Dynamics of maize nutrient uptake and accumulation in different regions of northern China. Plant 
Nutr Fert Sci, 2008, 14: 623-629 (in Chinese with English abstract).

[19］鲍士旦. 土壤农化分析. 北京: 中国农业出版社, 1999. pp 268-270.

Bao S D. Soil Agrochemical Analysis. Beijing: China Agriculture Press, 1999. pp 268-270 (in Chinese).

[20] 李波, 张吉旺, 靳立斌, 崔海岩, 董树亭, 刘鹏, 赵斌. 施钾量 对高产夏玉米产量和钾素利用的影响. 植物营养与肥料学报, 2012, 18: 832-838.

Li B, Zhang J W, Jin L B, Cui H Y, Dong S T, Liu P, Zhao B. Effects of $\mathrm{K}$ fertilization on yield, $\mathrm{K}$ use efficiency of summer maize under high yield conditions. Plant Nutr Fert Sci, 2012, 18: 832-838 (in Chinese with English abstract).

[21] 陆大雷, 刘小兵, 赵久然, 刘萍, 王凤格, 陆卫平, 张凯迪. 甜 玉米氮素吸收利用的基因型差异. 植物营养与肥料学报, 2008, 14: 258-263.

Lu D L, Liu X B, Zhao J R, Liu P, Wang F G, Lu W P, Zhang K D. Genotypic differences in nitrogen uptake and utilization of sweet maize. Plant Nutr Fert Sci, 2008, 14: 258-263 (in Chinese with English abstract).

[22] 易镇邪, 王璞, 陈平平, 屠乃美. 氮肥类型对夏玉米氮素吸收 和利用的影响. 植物营养与肥料学报, 2008, 14: 472-478.

Yi Z X, Wang P, Chen P P, Tu N M. Effect of different types of nitrogen fertilizer on nitrogen absorption and utilization of summer maize (Zea mays L.). Plant Nutr Fert Sci, 2008, 14: 472-478 (in Chinese with English abstract).

[23] 李伟, 李絮花, 李海燕, 彭强, 刘旭凤, 唐慎欣. 控释尿素与 普通尿素混施对夏玉米产量和氮肥效率的影响. 作物学报, 2012, 38: 699-706.

Li W, Li X H, Li H Y, Peng Q, Liu X F, Tang S X. Effects of different mixing rates of controlled-release urea and common urea on grain yield and nitrogen use efficiency of summer maize. Acta Agron Sin, 2012, 38: 699-706 (in Chinese with English abstract).

[24] 鲁艳红, 聂军, 廖育林, 周兴, 谢坚, 汤文光, 杨曾平. 不同控 释氮肥减量施用对双季水稻产量和氮素利用的影响. 水土保 持学报, 2016, 30(2): 155-161.

Lu Y H, Nie J, Liao Y L, Zhou X, Xie J, Tang W G, Yang Z P. Effects of application reduction of controlled release nitrogen fertilizer on yield of double cropping rice and nitrogen nutrient uptake. J Soil Water Conserv, 2016, 30(2): 155-161 (in Chinese with English abstract).

[25] Lang M, Christie P, Zhang J, Li X. Long-term phosphorus application to a maize monoculture influences the soil microbial community and its feedback effects on maize seedling biomass. Appl Soil Ecol, 2018, 128: 12-22.

[26] 江帆, 张玉平, 李安乡, 曾新保, 陈历儒, 陈红日. 不同磷肥 用量对玉米产量及磷素流失的影响. 天津农业科学, 2019, 25(3): 50-55.

Jiang F, Zhang Y P, Li A X, Zeng X B, Chen L R, Chen X R. Effect of different amount of phosphate fertilizer on corn yield and phosphorus loss. Tianjin Agric Sci, 2019, 25(3): 50-55 (in Chinese with English abstract).

[27] Wang X C, Deng X Y, Pu T, Song C, Yong T, Yang F, Liu J. Contribution of interspecific interactions and phosphorus application to increasing soil phosphorus availability in relay intercropping systems. Field Crops Res, 2017, 204: 12-22.

[28] 张白鸽, 陈琼贤, 罗少波, 李强, 曹健, 张敏强, 钟玉娟, 杨秋. 广州地区甜玉米测土配方施肥指标体系研究. 广东农业科学,
2012, (20): 46-48.

Zhang B G, Chen Q X, Luo S B, Li Q, Cao J, Zhang M Q, Zhong Y J, Yang Q. Research on index system for sweet maize fertilization by soil testing in Guangzhou. Guangdong Agric Sci, 2012, (20): 46-48 (in Chinese with English abstract).

[29] 李青军, 张炎, 哈丽哈什·依巴提, 冯固. 棉花高产和磷高效的 磷肥基施追施配合技术研究. 植物营养与肥料学报, 2018, 24: 146-153.

Li Q J, Zhang Y, Harlhax Yibat, Feng G. Basal and topdressing application technology of phosphate fertilizer for high cotton yield and high phosphorous efficiency in Xinjiang. Plant Nutr Fert Sci, 2018, 24: 146-153 (in Chinese with English abstract).

[30] 夏瑶, 娄运生, 杨超光, 梁永超. 几种水稻土对磷的吸附与解 吸特性研究. 中国农业科学, 2002, 35: 1369-1374.

Xia Y, Lou Y S, Yang C G, Liang Y C. Characteristics of phosphate adsorption and desorption in Paddy soils. Sci Agric Sin, 2002, 35: 1369-1374 (in Chinese with English abstract).

[31] 金金金, 曾新颖, 齐昌国, 尹黎燕, 邓燕. 供磷水平对玉米丛枝 菌根侵染及其对异质养分吸收的影响. 植物营养与肥料学报, 2018, 24: 163-169.

Jin X, Zeng X Y, Qi C G, Yin L Y, Deng Y. Influences of phosphorus application level on maize arbuscular mycorrhizal colonization and hyphal acquisition to heterogeneous phosphorus supply. Plant Nutr Fert Sci, 2018, 24: 163-169 (in Chinese with English abstract).

[32] 黄岩, 曹国军, 耿玉辉, 韩圆圆. 降水量与施磷量对黑土区玉 米产量及磷素吸收利用的影响. 玉米科学, 2018, 26(1): 142-148.

Huang Y, Cao G J, Geng Y H, Han Y Y. Effects of precipitation and phosphorus application rate on yield and phosphorus absorption and utilization of maize in black soil region. J Maize Sci, 2018, 26(1): 142-148 (in Chinese with English abstract).

[33] 吴启华, 刘晓斌, 张淑香, 尹彩侠, 李桂花, 谢佳贵. 施用常 规磷水平的 $80 \%$ 可实现玉米高产、磷素高效利用和土壤磷平 衡. 植物营养与肥料学报, 2016, 22: 1468-1476.

Wu Q H, Liu X B, Zhang S X, Yin C X, Li G H, Xie J G. Application of $80 \%$ of routine phosphorus rate to keep high yield and $\mathrm{P}$ efficiency of maize and P balance in soil. Plant Nutr Fert Sci, 2016, 22: 1468-1476 (in Chinese with English abstract).

[34] 钟新科, 刘洛, 徐新良, 游松财. 近 30 年中国玉米气候生产潜 力时空变化特征. 农业工程学报, 2012, 28(15): 94-101.

Zhong X K, Liu L, Xu X L, You S C. Characteristics of spatial-temporal variation of maize climate productivity during last 30 years in China. Trans CSAE, 2012, 28(15): 94-101 (in Chinese with English abstract).

[35] Saseendran S A, Ma L, Nielsen D C, Vigil M F, Ahuja L R. Simulating planting data effects on corn production using RZWQM and CERES-Maize models. Agron J, 2005, 97: 58-71.

[36] Kwabiah A B. Growth and yield of sweet corn (Zea mays L.) cultivars in response to planting date and plastic mulch in a short-season environment. Sci Hortic, 2004, 102: 147-166.

[37] 杨欢, 赵浚宇, 施凯, 施燕凌, 陆大雷, 陆卫平. 磷素施用对 鲜食糯玉米养分积累分配和产量的影响. 玉米科学, 2016, 24(1): 148-155.

Yang H, Zhao J Y, Shi K, Shi Y L, Lu D L, Lu W P. Effects of phosphorus application on nutrient uptake and distribution and grain yield of fresh waxy maize. J Maize Sci, 2016, 24(1): 148-155 (in Chinese with English abstract). 